03

\title{
Математическое моделирование течения газа в окрестности открытого торца трубы при колебаниях поршня на другом конце трубы по гармоническому закону на резонансной частоте
}

\author{
(C) С.В. Булович \\ Санкт-Петербургский политехнический университет Петра Великого, \\ 194021 Санкт-Петербург, Россия \\ e-mail: bulovic@yandex.ru
}

(Поступило в Редакцию 31 октября 2016 г. В окончательной редакции 2 мая 2017 г.)

В результате численного интегрирования двумерных уравнений Навье-Стокса в пакете программ ANSYS FLUENT установлена структура течения газа в окрестности открытого торца трубы при осциллирующем движении газа в трубе, вызванного колебаниями поршня на первой резонансной частоте. Для варианта трубы, характеризующегося фланцем „бесконечной“ протяженности и острой кромкой, исследовано влияние амплитуды смещения поршня на расход газа в трубе; определены фазы натекания и истечения газа за период колебания.

DOI: 10.21883/JTF.2017.11.45121.2086

\section{Введение}

Работа ряда технических устройств основана на возбуждении колебаний газа в резонаторе в виде тупикового участка трубы или объема с подводящим каналом, который сообщается с окружающим пространством. Представляет интерес как течение газа внутри резонатора, так и возникающее течение газа в окружающем пространстве. Для внутренних течений осциллирующее движение газа способствует интенсификации тепло- и массообменных процессов, что в общем случае позволяет уменьшить массогабаритные характеристики устройства. Течение газа в окрестности открытого конца резонатора приводит к формированию так называемой синтетической струи, которая по своим характеристикам существенно отличается от ее стационарного варианта. Для пристенных течений ортогональное к направлению потока применение синтетической струи позволяет управлять положением точки отрыва потока от поверхности. При нормальном взаимодействии синтетической струи с поверхностью существуют режимы, когда коэффициент теплоотдачи увеличивается на порядок.

Простейший вариант резонатора представляет собой тупиковый участок цилиндрической трубы, в котором колебания газового столба возбуждаются при помощи расположенного на торце трубы поршня, совершающего движение по синусоидальному закону.

Осциллирующее течение газа в трубе на резонансной частоте колебаний рассматривалось в литературе для замкнутых труб и труб, открытых с одного конца. Режим течения газа для такого класса потоков определяется тремя факторами - близостью частоты колебаний к резонансной частоте (число Струхала), скоростью движения поршня (число Маха) и влиянием пограничного слоя на стенке трубы на ядро потока (число Стокса). В зависимости от сочетания перечисленных факторов возможны резонансные (с образованием или без образования ударно-волновой структуры) или далекие от резонанса ламинарные или турбулентные режимы течения.

В случае открытого торца трубы на поведение решения будет оказывать дополнительное влияние состояние газа в окружающем конец трубы пространстве (импеданс). Помимо этого, характер течения газа в трубе будет зависеть от геометрических характеристик соединения трубы и окружающего пространства форма кромки трубы (радиус закругления в отношении к диаметру трубы), толщина стенки трубы (диаметр фланца в отношении к диаметру трубы).

В конечном счете, полнофакторный учет всех перечисленных режимных и геометрических параметров рассматриваемой системы представляет собой сложную нелинейную задачу. При математической формулировке задачи существенным моментом является выбор положения границы расчетной области и используемые на этой границе граничные условия. Классический подход позволяет сформировать граничные условия непосредственно на торце трубы. При этом принято разделять граничные условия для натекания газа в трубу и граничные условия при истечении газа из трубы. На стадии натекания газа в трубу исходят из допущения о потенциальном режиме течения газа. Давление и температура торможения служат точкой отсчета для соответствующих функций. При истечении газа из трубы считается, что структура течения газа может быть описана в рамках нестационарной струи. Источник струи имеет переменный расход, и истечение газа происходит на заданный уровень давления в окружающем торец трубы пространстве.

Циклическую смену перечисленного набора граничных условий можно характеризовать как вариант квазистационарного подхода в реализации граничных условий. Связано это с тем, что при расчете следующего цикла 
колебаний не в полной мере используется информация о предыдущем состоянии газодинамических функций в трубе и окружающем пространстве.

Классический подход использования граничных условий позволяет получить аналитическое решение рассматриваемой задачи. Выделим ряд отечественных $[1,2]$ и зарубежных $[3,4]$ работ. В этих работах через граничное условие на торце трубы последовательно совершенствовались представление о механизме связи между решением задачи в трубе и продолжением решения в окружающем пространстве. Экспериментально и теоретически (в рамках аналитического подхода) вопросы влияния геометрических факторов сочленения трубы и окружающего пространства на характеристики течения газа в трубе рассматривались в работах $[5,6]$.

Укажем на недостатки классического подхода. Во-первых, смена направления потока происходит не одновременно во всем сечении трубы. В момент времени, когда на торце трубы возникает нулевое значение расхода, это состояние, как правило, обеспечивается разнонаправленными потоками на оси трубы и в окрестности стенки трубы. Во-вторых, при натекании газа в трубу внутри трубы формируется приосевой вихрь тороидальной формы. Подробно характеристики этого вихря экспериментально были исследованы в работе [7]. В-третьих, фаза истечения газа из трубы в большей степени характеризуется не структурой осциллирующего течения в трубе, а удалением из трубы вышеназванного приосевого вихря тороидальной формы. В-четвертых, нестационарное истечение газовой струи сопровождается образованием наружного вихревого кольца в окрестности торца трубы с противоположным по отношению к тороидальному приосевому вихрю направлением вращения. Сочетание перечисленных явлений приводит к возникновению в направлении оси трубы синтетической струи. Таким термином принято обозначать струйное течение от источника с нулевым расходом газа через источник. Характеристики синтетической струи зависят от режима течения газа на торце трубы. Заметим, что, в свою очередь, синтетическая струя оказывает обратное влияние на течение газа в трубе, поэтому формулировка граничного условия на открытом торце трубы разрывает эту связь.

Постановка задачи существенно упростится, если граничные условия будут сформулированы на „бесконечности“, когда волны разрежения и сжатия, излучаемые с открытого торца трубы, теряют свою интенсивность. На значительном удалении от открытого торца трубы можно использовать традиционные граничные условия для дозвуковых потоков сжимаемых сред на проницаемых участках границы: для входного участка границы определены значения давления и температуры торможения, для выходного участка границы определен уровень давления.

Опираясь на вышесказанное, целью настоящей работы является иллюстрация возможности математического моделирования закономерностей поведения газа в окрестности открытого торца трубы (генератора синтетической трубы) в рамках двумерной осесимметричной постановки на резонансной частоте колебаний.

\section{Постановка задачи}

Основные характеристики расчетной области: диаметр трубы - $0.04 \mathrm{~m}$, длина трубы - $1 \mathrm{~m}$, радиус примыкающей к трубе полусферы - $1.5 \mathrm{~m}$. Амплитуда смещения поршня $a=(0.25-2.0) \cdot 10^{-3} \mathrm{~m}$. В цилиндрической системе координат закон перемещения плоской поверхности поршня описывается функцией $z=a \cos (\omega t)$.

На стенках трубы, фланце и поршне задавалось граничное условие первого рода для компонент вектора скорости и температуры. Скорость газа совпадала со скоростью движения поверхности, температура стенки равна $300 \mathrm{~K}$. На проницаемых границах расчетной области давление и температура торможения были заданы значениями $10^{5} \mathrm{~Pa}$ и $300 \mathrm{~K}$ соответственно.

Рассмотренные параметры задачи исключают возможность турбулентного режима течения в трубе. Для описания характеристик возможных турбулентных режимов течения газа в окружающем пространстве была использована модель Спаларта-Аллмареса, допускающая возможность спонтанного перехода к турбулентному режиму течения.

Расчет вариантов, характеризующихся различной амплитудой смещения поршня, начинался от однородного состояния газодинамических функций, равных их значениям в граничных условиях, и продолжался до установившихся циклических изменений функций.

Для дискретизации задачи была использована структурированная сетка, состоящая из четырехугольных элементов. Для разрешения пограничных слоев использовалось сгущение сетки к твердым поверхностям. Связанное с перемещением поршня изменение размеров расчетной области было реализовано в рамках процедуры „Dynamic Mesh>In-Cylinder“ пакета программ ANSYS FLUENT за счет соответствующей коррекции количества элементов дискретизации и/или их формы. В версии программы ANSYS FLUENT 16.2 численное интегрирование двумерных нестационарных уравнений Навье-Стокса, записанных в осесимметричной постановке, возможно с третьим порядком точности по пространству и вторым порядком точности по времени.

\section{Результаты расчетов}

Определение собственной частоты колебаний системы было проведено опытным путем. Для этого была рассмотрена задача опорожнения тупикового участка трубы, находящегося при избыточном $\left(1.01 \cdot 10^{5} \mathrm{~Pa}\right)$ по сравнению с окружающей средой давлении. На рис. 1 приведены зависимости расхода газа через торец трубы и значения осевой составляющей скорости на оси симметрии в точках мониторинга: срез трубы (P1) и 

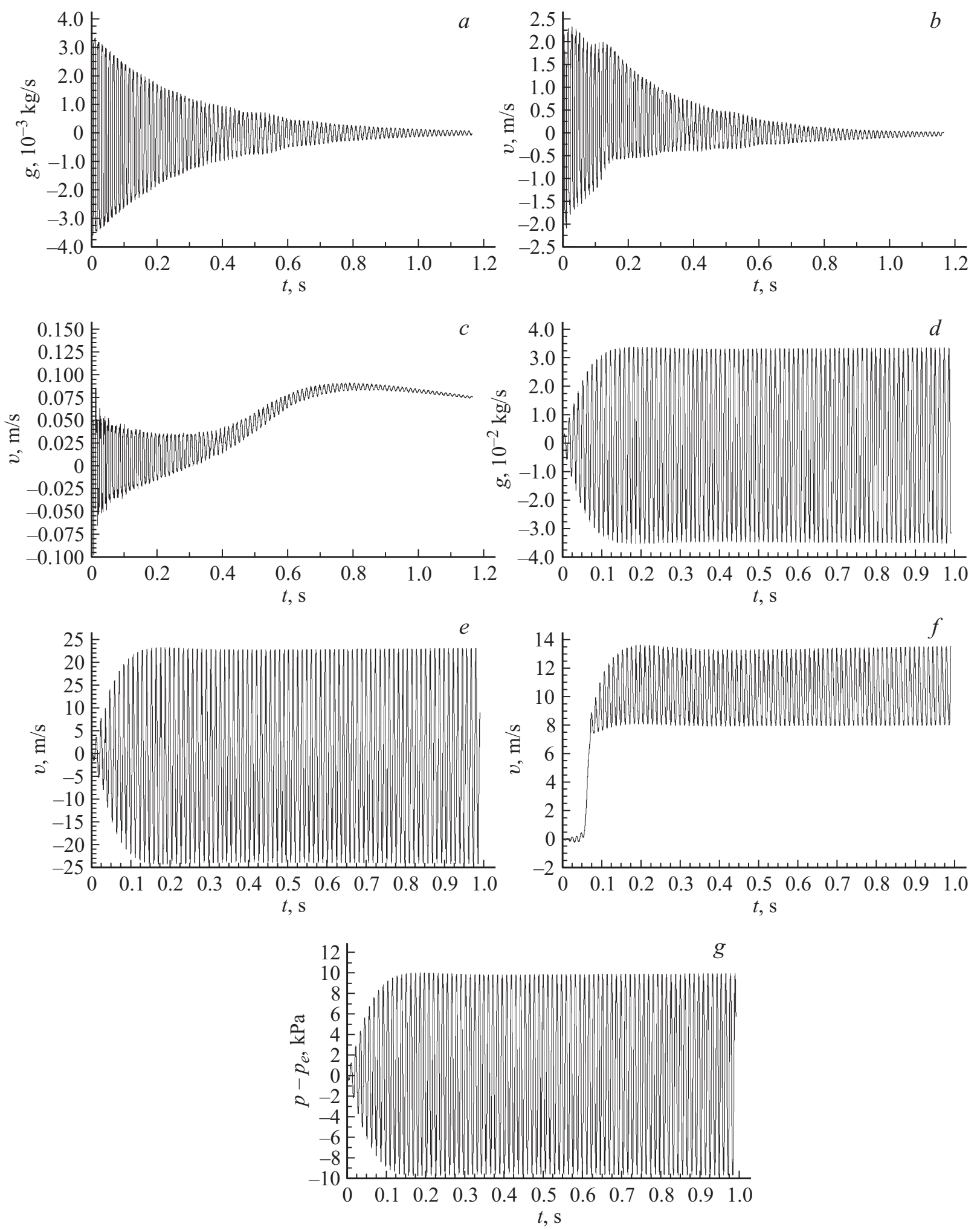

Рис. 1. Расход газа на срезе трубы $(a, d)$, скорость газа в точках $\mathrm{P} 1(b, e)$ и $\mathrm{P} 2(c, f)$ в зависимости от времени: $g-$ отклонение давления на поверхности поршня от значения давления в окружающем пространстве; $a-c-$ режим автоколебаний, $d-g-$ амплитуда смещения поршня $a=2.0 \cdot 10^{-3} \mathrm{~m}$.

на расстоянии 2.5 диаметра трубы (Р2). Приведенные зависимости (более 100 циклов колебаний газа) отчетливо демонстрируют на первых циклах колебания газового столба вырождение высокочастотных гармоник. Заключительные затухающие колебания газа малой амплитуды имеют синусоидальную форму и происходят 

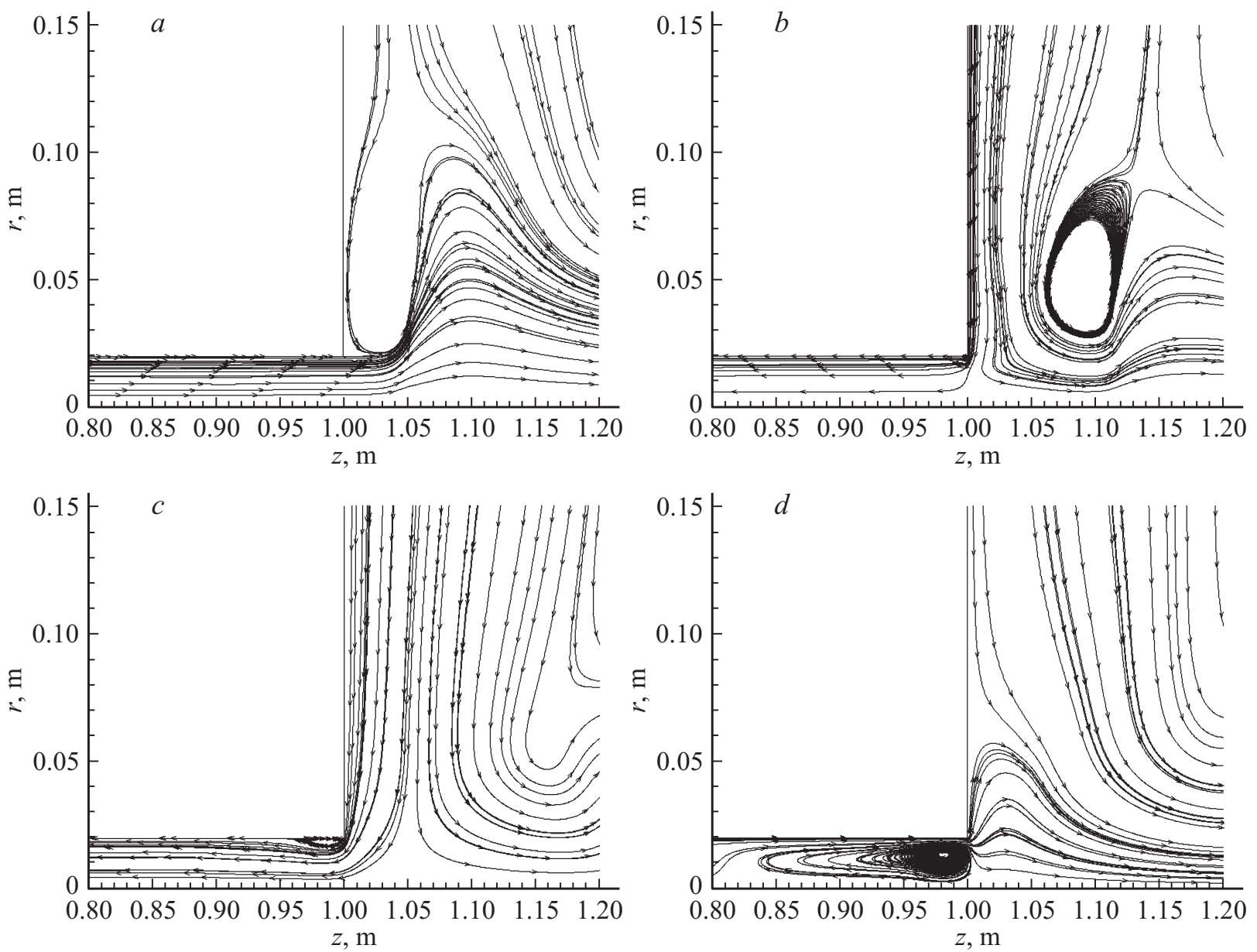

Pис. 2. Мгновенные линии тока при фазовом угле $15^{\circ}$

$(a), 105^{\circ}(b), 195^{\circ}(c)$ и $285^{\circ}(d)$. (Масштаб $\left.z: r=1: 2.\right)$

на собственной частоте. По графику изменения расхода газа на торце трубы (рис. $1, a)$ устанавливался период колебаний газа. Собственную частоту колебаний газового столба можно оценить в $86 \mathrm{Gz}$. Заметим, что эта величина зависит от уровня потерь в рассматриваемой системе. Можно ожидать, что с увеличением амплитуды смещения поршня будет возрастать уровень потерь в рассматриваемой системе и значение собственной частоты колебаний системы должно смещаться в область более низких частот. Рис. $1, b$ свидетельствует об асимметричности осевой составляющей скорости в режиме автоколебаний при натекании газа и его истечении из тупикового участка трубы. По поведению функции на рис. 1, $c$ можно судить о формировании синтетической струи даже в режиме автоколебаний и ее последующем затухании в связи с уменьшением амплитуды колебаний газа в трубе.

Проиллюстрируем решение рассматриваемой задачи для варианта амплитуды смещения поршня $a=$ $=2.0 \cdot 10^{-3} \mathrm{~m}$. На рис. $1, d-g$ представлены расход газа на срезе трубы, значения осевой составляющей скорости в точках мониторинга и отклонение давления на поверх- ности поршня от давления в окружающем пространстве в зависимости от времени.

Анализ установившегося цикла колебаний принято иллюстрировать четырьмя фазовыми состояниями. Течение газа в окрестности торца трубы нестационарное, поэтому воспользуемся для визуализации его структуры мгновенными значениями линий тока. Для лучшего восприятия полученного решения поперечные размеры области увеличены в два раза. На рис. 2, $a$ приведена первая фаза - истечение струи газа из трубы в окружающее пространство. Вокруг струи начинает формироваться вихревое кольцо. Следующая фаза (рис. 2, $b$ ) момент смены направления расхода газа через торец трубы. При нулевом расходе газа через торец трубы в окрестности стенки газ поступает в трубу, в окрестности оси трубы продолжается истечение газа. Сформированное вихревое кольцо, окружающее нестационарную струю газа, увеличивается в поперечном размере и смещается в осевом направлении. Третья фаза иллюстрирует структуру течения при поступлении газа в трубу. Отчетливо видно, что натекание газа в трубу происходит преимущественно в плоскости торца трубы с резким разворотом потока на $90^{\circ}$ (рис. $2, c$ ). При этом 
внутри трубы формируется приосевой вихрь тороидальной формы. Четвертая фаза - изменение направления движения газа на срезе трубы и начало формирования газовой струи. Тороидальный вихрь оттесняется к оси трубы и выводится за ее пределы (рис. 2, $d$ ).

\section{Заключение}

В результате численного интегрирования по времени уравнений Навье-Стокса, записанных в цилиндрической системе координат, получено представление о структуре течения газа на открытом торце трубы. Для рассмотренного варианта амплитуды смещения поршня резонансные колебания расхода газа на торце трубы отстают по фазе на угол $105^{\circ}$ относительно смещения поверхности поршня. Поступление газа в трубу происходит в интервале значений фазового угла $105^{\circ}-285^{\circ}$. При установившихся резонансных колебаниях скорость газа на срезе трубы на оси симметрии имеет одинаковую амплитуду при истечении и поступлении газа. В окружающем пространстве за срезом трубы в направлении ее оси формируется синтетическая струя.

Работа выполнялась в рамках проекта 3.3314.2017/4.6 государственного задания Министерства образования и науки РФ на период 2017-2019 гг.

\section{Список литературы}

[1] Галиуллин Р.Г., Пермяков Е.И., Галиуллина Э.Р. // Акустический журнал. 1996. Т .42. № 6. С. 769-772.

[2] Галиуллин Р.Г., Ткаченко Л.А., Филиппов С.Е., Галиуллина Э.Р. // Инженерно-физический журнал. 2004. Т. 77. № 1. C. $109-113$.

[3] Disselhorst J.H.M., Wijngaarden L. Van // J. Fluid Mech. 1980. Vol. 99. N 2. P. 293-319.

[4] Keller J.J. // J. Appl. Mathemat. Phys. (ZAMP). 1982. Vol. 33. P. $489-510$.

[5] Ткаченко Л.А., Галиуллин Р.Г. // Известия вузов. Авиационная техника. 2010. № 1. С. 31-33.

[6] Репина А.В., Галиуллин Р.Г. // Известия вузов. Авиационная техника. 2008. № 1. С. 33-36.

[7] Васильев Л.С., Зарипов Р.Г., Магсумова А.Т., Сальянов O.P. // Инженерно-физический журнал. 1991. Т. 61. № 8. C. 714-716. 